\title{
Leisure-time physical activity among university students in Mauritius
}

\author{
Marie CHAN SUN ${ }^{1}$, Kawthur B. AZMUTALLY ${ }^{2}$ \\ ${ }^{1}$ Faculty of Science, University of Mauritius, Reduit, MAURITIUS \\ ${ }^{2}$ Ministry of Health and Quality of Life of Mauritius, Port Louis, MAURITIUS
}

Email address:

lan.sun@uom.ac.mu (Marie C. S.)

To cite this article:

Marie CHAN SUN, Kawthur B. AZMUTALLY. Leisure-Time Physical Activity among University Students in Mauritius. American Journal of Health Research. Vol. 1, No. 1, 2013, pp. 1-8. doi: 10.11648/j.ajhr.20130101.11

\begin{abstract}
Mauritius has Type 2 Diabetes mellitus as public health issue, whereby unhealthy modes of eating and sedentary lifestyles are factors to be addressed in the primary prevention of the disease among the youth. This study was thus designed to investigate the prevalence of Leisure-time physical activity (LTPA) among university students in Mauritius and to explore their motivations and constraints to engage in LTPA, using the ecological model of health promotion. Data were collected from a representative group of university students in Mauritius using a self-administered questionnaire. Qualitative and quantitative data pertaining to LTPA issues were collected. Three-fifths of the participants met the recommended levels of LTPA. The majority of inactive participants were female. Motivations provided by participants to engage in LTPA were predominantly intrapersonal. The three most mentioned motivations were improvement in physical health, improvement in physical appearance and to have fun. Constraints faced by participants to engage in LTPA were mainly of an intrapersonal nature. The three main constraints provided by students were lack of time, having to study and not being motivated. Therefore, interventions to promote LTPA among university students should simultaneously address development of time-management skills and provision of incentives to perform LTPA.
\end{abstract}

Keywords: Leisure-Time Physical Activity, Motivation, Constraint, University Students, Mauritius

\section{Introduction}

The World Health Organization (WHO) has identified 4 main opportunities that an individual can have to be physically active [1]. These are: (i) Physical activity (PA) at work (whether or not the work involves manual labor), (ii) PA for transport (walking or cycling to work, to shop, etc.), (iii) PA during domestic duties (housework, gathering fuel, etc) and (iv) Leisure-time PA (exercise, sports, physically active hobbies and recreational activities) [1]. The WHO has also identified physical inactivity as the fourth leading risk factor for global mortality, with physical inactivity being estimated to be the main cause for around $30 \%$ of ischemic heart disease burden, about $21-25 \%$ of breast and colon cancers, and $27 \%$ of diabetes [2].

Type 2 Diabetes mellitus is a public health issue in Mauritius [3], which is an island situated in the Indian Ocean. Mauritius had in 2010 the fourth highest prevalence of Type 2 Diabetes mellitus in the world [4], which has increased by $64 \%$ over 22 years in Mauritius [5]. In fact, the prevalence of diabetes in the Mauritian population aged 25-74 years is currently $23.6 \%$ [6], whereas prevalence of physical exercise remains low [6]. Only $16.5 \%$ of Mauritian adults aged $25-74$ years $(10.9 \%$ women and $23.2 \%$ men) performed sufficient leisure time physical activity to meet the national guidelines of 30 minutes of moderate and/or vigorous physical exercise per day to maintain good health [6]. More than one out of two Mauritians, more precisely, $56.2 \%$, with $65.8 \%$ of women and $45.7 \%$ of men, reported no participation at all in moderate or vigorous leisure time physical activity [6]. In fact, this prevalence has not increased since the previous Non Communicable Diseases Survey in 2004, which showed that only $10 \%$ of women and $25 \%$ of men perform leisure-time physical exercise [7].

The sedentary lifestyles of Mauritians are factors which need to be addressed in the primary prevention of the Type 2 Diabetes mellitus among the youth. Caspersen et al. reported that the decline of physical activity in young people is most visible from 15 to 18 years old [8]. According to Bray and Born, the number of young people who do not implement intensive physical activity around the period of high school graduation, or when they enter university, decreases by a 
significant degree [9]. PA patterns established by university students need to be addressed because it is likely that they will persist or even decline in the years following graduation [10]. University students who are now inactive have a high probability to be inactive after they leave university. University students are the researchers, health professionals, business leaders, and policy makers of tomorrow [11]. Therefore, future societal norms and values regarding health and PA behavior may be influenced by the habits, beliefs, and attitudes adopted by this important subgroup of the population.

An ecological approach to this health issue has been used in this study to analyze the factors influencing LTPA behavior of university students. The ecological model is a comprehensive health promotion model that is multifaceted, concerned with environmental changes, behavior and policy that help individuals make healthy choices in their daily lives [12]. In particular, the resurgence of interest into social inequalities in health has directed interest into the central role of larger contextual determinants of health, such as socioeconomic factors, gender, and other social and cultural influences [13]. There are two major areas of importance in the ecological model, personal and environmental factors. Personal factors can be broken down into intrapersonal factors and interpersonal factors. Environmental factors, on the other hand can be further subdivided into three levels: institutional, community, and public policy. The most effective intervention aiming at improving health behaviour would be one that brings about necessary changes at all levels mentioned above.

The objectives of the current study were to investigate the prevalence of LTPA among a group of university students and to explore the motivations and constraints faced by these individuals to engage in LTPA, using the ecological model of health promotion. For explorative purposes, a qualitative approach was used to investigate the motivations and constraints behind LTPA participation.

\section{Methods}

\subsection{Study Population}

This descriptive study was carried among full-time university students in Mauritius, aged between 18-25 years old. Proportionate stratified random sampling method was used in order to achieve a representative sample of full time university students, aged between 18-25 years. Strata used were gender and faculties. The sample size was 358 participants $($ Males $=159$; Females $=199)$.

\subsection{Survey Instrument}

A self-administered questionnaire adapted from the Global Physical Activity Questionnaire (GPAQ) developed by WHO [14] was used for data collection.

\subsection{Study Variables}

\subsubsection{LTPA score}

Data on the intensity, frequency, and duration of PA performed during leisure-time in a typical week were obtained. Responses were summed to create an LTPA score, expressed in metabolic equivalent (MET). The formula below [15] was used to calculate the LTPA score of participants:

$$
\begin{gathered}
\text { Weekly LTPA } \\
\text { Score }
\end{gathered}=\begin{gathered}
\text { MET level x minutes of } \\
\text { activity/day } \\
\text { x days per week }
\end{gathered}
$$

(expressed as MET-min per week)

Intensity of physical activity was categorized into three levels, namely light, moderate and vigorous, based on the classification of the Centre of Disease Control and Prevention (CDC) [16]. Vigorous, moderate and light-intensity LTPA were attributed a value of 8,4 and 3.3 MET respectively [16].

The term "leisure" was reiterated every time when physical activity was mentioned so that participants did not include non-leisure-time physical activities (transportation, domestic and PA at work) when responding to the questionnaire.

\subsubsection{Qualitative Data}

For explorative purposes, a qualitative approach through the use of open-ended questions was used to investigate the motivations and constraints that students face to engage in LTPA. Participants were given sufficient space to answer. Those who wanted to write more could do so at the back of the page.

\subsection{Data Collection and Ethical Considerations}

Upon approval by the institutional ethics committee, data collection was carried out over a period of two months. A participation information sheet was provided and the aims and importance of the study were explained to participants. Written consent was obtained from each participant prior to start of questionnaire survey. Anonymity and confidentiality were maintained throughout the research process.

\subsection{Data Processing and Analysis}

"LTPA status" was dichotomized into "active" $(\geq 600$ METs-min/week), and "inactive" (<600 METs-min/week). The threshold between these two status has been calculated based on the recommendations that adults should engage in physical activity at least 5 days per week, 30 minutes per session (which amount to $600 \mathrm{METs}-\mathrm{min} /$ week), in order to maintain good health [17] [18].

Qualitative data were examined for common themes. Coding categories related to intrapersonal, interpersonal, and environmental factors influencing LTPA behaviors among university students were developed. Within each category, major themes were developed. Answers given by 
participants were coded double-checked. Data entry and statistical analysis was performed using Epi-info software (Epi-Info $^{\mathrm{TM}}$, Centers for Disease Control and Prevention). Responses from the active group and the inactive group were compared.

\section{Results}

The demographic data of participants are shown in Table 1.

Table 1. Demographic data of participants

\begin{tabular}{|c|c|c|c|c|c|c|c|}
\hline \multirow{2}{*}{ Characteristics } & \multirow[t]{2}{*}{ Total } & \multicolumn{3}{|c|}{ Active LTPA } & \multicolumn{3}{|c|}{ Inactive LTPA } \\
\hline & & No. & $\%$ & $\mathrm{CI}$ & No. & $\%$ & $\mathrm{CI}$ \\
\hline $\begin{array}{l}\text { Total no. of } \\
\text { Participants }\end{array}$ & 358 & 212 & 59.2 & $53.9-64.3$ & 146 & 40.8 & $35.7-46.1$ \\
\hline \multicolumn{8}{|c|}{ Gender } \\
\hline Male & 159 & 130 & 61.3 & $54.4-67.9$ & 29 & 19.9 & $13.7-27.3$ \\
\hline Female & 199 & 82 & 38.7 & $32.1-45.6$ & 117 & 80.1 & $72.7-86.3$ \\
\hline \multicolumn{8}{|c|}{ Ethnic origin } \\
\hline Afro-Mauritian & 23 & 15 & 7.1 & $4.0-11.4$ & 8 & 5.5 & $2.4-10.5$ \\
\hline Indo-Mauritian & 308 & 182 & 85.8 & $80.4-90.2$ & 126 & 86.3 & $79.6-91.4$ \\
\hline Sino-Mauritian & 9 & 5 & 2.4 & $0.8-5.4$ & 4 & 2.7 & $0.8-6.9$ \\
\hline \multicolumn{7}{|c|}{ BMI } & $2.4-10.5$ \\
\hline Underweight & 100 & 54 & 25.5 & $19.8-31.9$ & 46 & 31.7 & $24.3-40.0$ \\
\hline Normal weight & 221 & 136 & 64.2 & $57.3-70.6$ & 85 & 58.6 & $50.2-66.7$ \\
\hline Overweight & 33 & 20 & 9.4 & $5.9-14.2$ & 13 & 9 & $4.9-14.8$ \\
\hline Obese & 1 & 1 & 0.5 & $0.0-2.6$ & 0 & 0 & $0.0-2.5$ \\
\hline Severe obesity & 2 & 1 & 0.5 & $0.0-2.6$ & 1 & 0.7 & $0.0-3.8$ \\
\hline \multicolumn{8}{|c|}{ Residential area } \\
\hline Urban & 185 & 124 & 58.5 & $51.5-65.2$ & 61 & 41.8 & $33.7-50.2$ \\
\hline Rural & 173 & 88 & 41.5 & $34.8-48.5$ & 85 & 58.2 & $49.8-66.3$ \\
\hline \multicolumn{8}{|c|}{ Marital status } \\
\hline Single & 343 & 202 & 95.3 & $91.5-97.7$ & 141 & 96.6 & $92.2-98.9$ \\
\hline Cohabitating & 8 & 4 & 1.9 & $0.5-4.8$ & 4 & 2.7 & $0.8-6.9$ \\
\hline Married & 7 & 6 & 2.8 & $1.0-6.1$ & 1 & 0.7 & $0.0-3.8$ \\
\hline Divorced/widow & - & - & - & - & - & - & - \\
\hline
\end{tabular}

CI indicates $95 \%$ confidence interval; BMI, body mass index has been categorized as follows: a BMI of $<18.5=$ Underweight; $(18.5-24.9)=$ normal weight; $(25.0-29.9)=$ obese; $(30.0-34.9)=$ severe obesity

Table 2. Linkages between major themes and respondents' comments for motivations to engage in LTPA

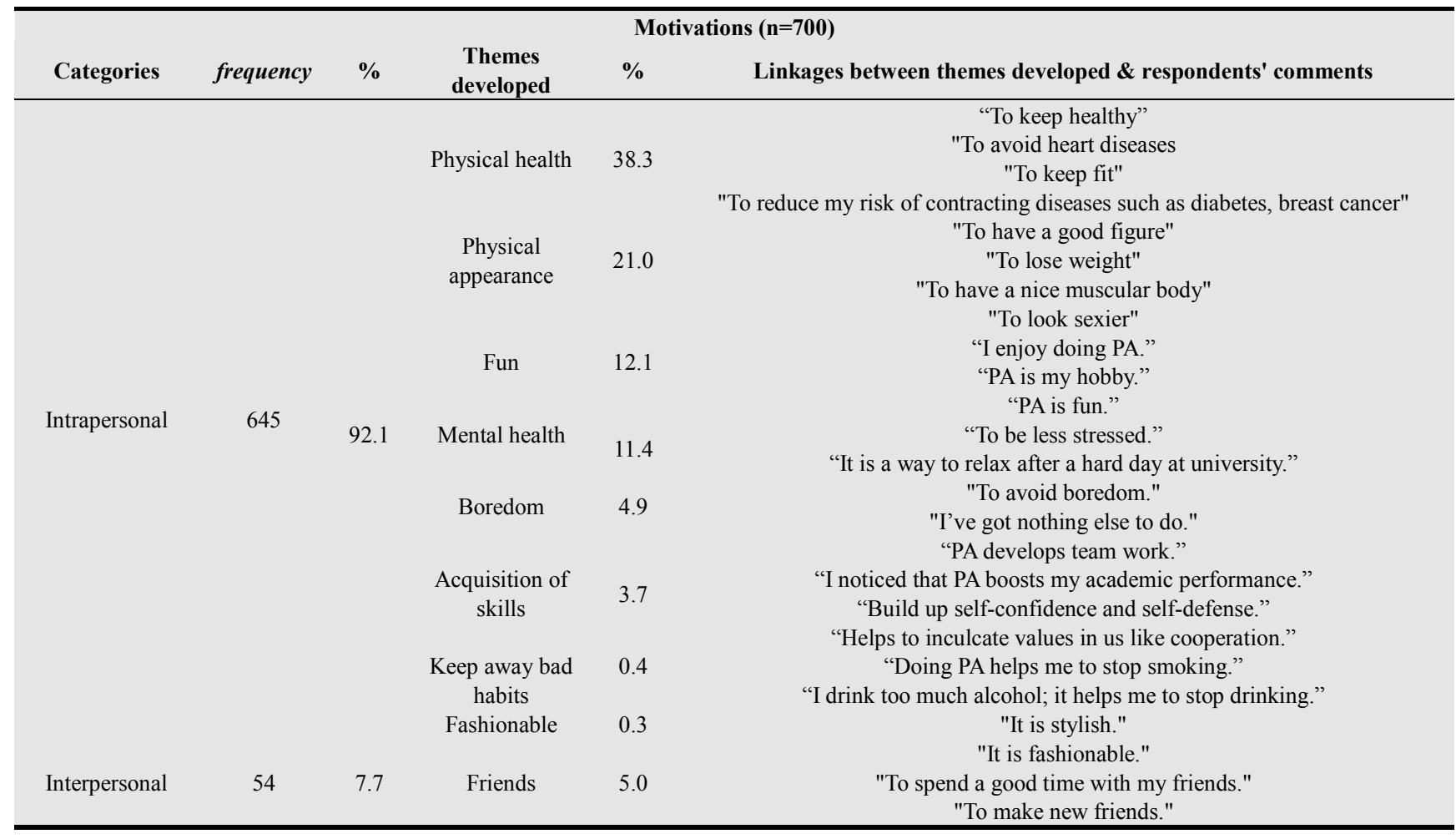




\begin{tabular}{|c|c|c|c|c|c|}
\hline & & & $\begin{array}{c}\text { Family } \\
\text { Girl/ Boyfriend }\end{array}$ & 2.3 & $\begin{array}{l}\text { "My parents encourage me to do so." } \\
\text { "To have a nice time with family." } \\
\text { "To please my girlfriend." } \\
\text { "To flirt with my girlfriend." }\end{array}$ \\
\hline Environmental & 1 & 0.1 & Facilities & 0.1 & $\begin{array}{l}\text { "I have a nice gym near my place with the latest exercise machines in it, and it } \\
\text { would be pity not to make good use of it." }\end{array}$ \\
\hline
\end{tabular}

$\mathrm{f}=$ frequency

Table 3. Linkages between major themes and respondents' comments for constraints to engage in LTPA

\begin{tabular}{|c|c|c|c|c|c|}
\hline \multicolumn{6}{|c|}{ Constraints $(\mathrm{n}=777)$} \\
\hline Categories & frequency & $\%$ & $\begin{array}{c}\text { Themes } \\
\text { developed }\end{array}$ & $\%$ & Linkages between themes developed \& respondents' comments \\
\hline \multirow{10}{*}{ Intrapersonal } & \multirow{10}{*}{650} & \multirow{10}{*}{83.7} & Time & 33.2 & $\begin{array}{c}\text { "Lack of time" } \\
\text { "I don't have much time to devote to PA" }\end{array}$ \\
\hline & & & Studies & 20.6 & $\begin{array}{l}\text { "Too many lectures, homework, projects, lab reports, assignments." } \\
\text { "I have more important things to do, such as studying." }\end{array}$ \\
\hline & & & Amotivation & 11.2 & $\begin{array}{l}\text { "I am not motivated." } \\
\text { "I am just too lazy" }\end{array}$ \\
\hline & & & Commitments & 5.7 & $\begin{array}{l}\text { "Family commitments." } \\
\text { "Social commitments." } \\
\text { "I am addicted to play station." }\end{array}$ \\
\hline & & & $\begin{array}{l}\text { Sedentary } \\
\text { leisure }\end{array}$ & 6.3 & $\begin{array}{c}\text { "There are many other activities apart from PA (smoking, drinking) that are more } \\
\text { pleasurable." } \\
\text { "Surfing on the net." }\end{array}$ \\
\hline & & & & & $\begin{array}{c}\text { "Other activities such as watching TV and playing games are more fun." } \\
\text { "I feel too tired to exercise." }\end{array}$ \\
\hline & & & Fatigue & 3.9 & $\begin{array}{l}\text { "I am afraid that I will be too tired after exercise \& therefore I won't be able to } \\
\text { concentrate on my studies." }\end{array}$ \\
\hline & & & Pain & 1.7 & $\begin{array}{c}\text { "PA is painful." } \\
\text { "I feel pain in my body after doing PA." }\end{array}$ \\
\hline & & & Money & 1.0 & $\begin{array}{l}\text { "The sports activities that I like cost me too much money." } \\
\text { "Cost of gym fees." }\end{array}$ \\
\hline & & & Lack of skills & 0.4 & $\begin{array}{l}\text { "Owing to my introvert nature, I hesitate to join others in PA." } \\
\text { "I don't have the ability required to do sports." }\end{array}$ \\
\hline \multirow{4}{*}{ Interpersonal } & \multirow{4}{*}{40} & \multirow{4}{*}{5.1} & Friends & 3.7 & $\begin{array}{l}\text { "Unavailability of friends who normally participate with me." } \\
\text { "Haven't got anyone to exercise with at times." }\end{array}$ \\
\hline & & & & & "My parents consider my sports practice to be dangerous." \\
\hline & & & & & "Lack of motivation from family members." \\
\hline & & & Family & 1.4 & $\begin{array}{c}\text { "Due to old-fashioned parents who think that PA is not for girls." } \\
\text { "Narrow-minded parents who think that girls are imitating boys while trying to jog } \\
\text { or lifting weights." }\end{array}$ \\
\hline \multirow{4}{*}{ Environmental } & \multirow{4}{*}{87} & \multirow{4}{*}{11.2} & Facilities & 8.4 & $\begin{array}{l}\text { "Lack of sports facilities." } \\
\text { "Absence of recreational facilities in the area where I live." } \\
\text { "The facilities are old \& dilapidated." }\end{array}$ \\
\hline & & & & & "Weather conditions; it's either too hot or too cold." \\
\hline & & & Cinmate & 2.0 & $\begin{array}{l}\text { "Because of the rain." } \\
\text { "The summer heat makes me feel dizzy." }\end{array}$ \\
\hline & & & Safety concerns & 0.3 & $\begin{array}{l}\text { "My locality is not safe enough to do PA outside." } \\
\text { "Presence of stray dogs on the road, especially in rural areas." }\end{array}$ \\
\hline
\end{tabular}

The mean LTPA duration among participants was $937 \pm$ $798 \mathrm{METs}-\mathrm{min} /$ week $(1446 \pm 638 \mathrm{METs}-\mathrm{min} /$ week for the active group; $195 \pm 201 \mathrm{METs}-\mathrm{min} /$ week for the inactive group). Recommended levels of LTPA were achieved by $59.2 \%$ of students $(81.5 \%$ of male students and $41.2 \%$ of female students). $17.6 \%$ of participants reported doing no LTPA at all (0 MET-min/week). $87.3 \%$ of those who reported doing no LTPA were female and the remaining $12.7 \%$ were male students.

\subsection{Results of Qualitative Data Analysis}

\subsubsection{Motivations}

A total of 700 reasons that motivate participants to do
LTPA were collected from the 358 questionnaires. These reasons were categorized into 3 main factors: intrapersonal, interpersonal and environmental factors. Among motivations given by participants, $92.1 \%$ (59.0\% from active group, $33.1 \%$ from inactive group) were intrapersonal, $7.7 \%$ interpersonal $(6.0 \%$ from active group, $1.7 \%$ from inactive group), and $0.1 \%$ environmental $(0.1 \%$ from active group).

Linkages between major themes developed and respondents' comments for motivations to engage in LTPA are provided in Table 2. The three main intrapersonal motivations reported were improvement in physical health, improvement in physical appearance and fun, respectively. 
Mental well-being, to avoid boredom, to acquire skills, to keep away from unhealthy habits and to be fashionable, were the other major themes developed under the category of intrapersonal motivations. Under the interpersonal category, participants identified friends as a motivational factor rather than family members for engaging in LTPA.

\subsubsection{Constraints}

Participants had put forward 777 reasons as constraints hindering them from doing LTPA. These answers were categorized into 3 main factors intrapersonal, interpersonal and environmental factors. $83.7 \%$ (50.3\% from active group, $33.3 \%$ from inactive group) of the constraints faced by participants to engage in LTPA were intrapersonal, $5.1 \%$ of the constraints were interpersonal (3.4\% from active group, $1.7 \%$ from inactive group) and the remaining $11.2 \%$ were environmental constraints $(6.6 \%$ from active group, $4.6 \%$ from inactive group).

Linkages between major themes developed and respondents' comments for constraints to engage in LTPA are provided in Table 3. The three main intrapersonal constraints provided by students were lack of time, having to study and not being motivated, respectively. Unavailability of friend(s) or partner(s) with whom to do LTPA was the main interpersonal constraints provided by participants, followed by the lack of support from parents. Lack of recreational facilities was the major environmental constraints identified by participants to engage in LTPA. Climatic conditions and safety concerns were the other two major themes developed under the environmental constraint category.

\section{Discussion}

The Ecological Model of Health promotion guided this study of factors that influence the practice of LTPA among a group of university students. Three major areas were developed: intrapersonal factors, interpersonal factors and environmental factors.

\subsection{LTPA Status}

Overall, this study shows that three out of five students reached the recommended level of LTPA (a minimum of 600 METs-min/week). One out of five students reported doing no LTPA at all (0 MET-min/week). Compared to the research work carried out by Haase et al. [19] among 19,298 university students from 23 countries, our data show that university students in Mauritius are slightly more active. This difference can be attributed to the fact that the criterion used to classify an individual as active or inactive in the present study was different from that used by Haase et al. [19]. The criterion used to classify an individual as active in the present study was spending at least 600 METs-min/week which is equivalent to engaging in 30 minutes of PA for at least 5 days per week. This criterion was chosen based on the latest recommendation on physical activity made by major international health organizations namely, the CDC [20] and
WHO [17] for the maintenance of good health. In addition, in the previous study [19], university students up to the age of 30 years old were included. In the present study, participants were all full-time students aged between 18-25 years. In view of the younger age group of participants, it may be hypothesized that these individuals would have more opportunities to engage in LTPA, hence explaining the slightly higher rate of prevalence of LTPA among the studied sample.

Whereas it is encouraging that almost three-fifth of participants engage in 30 minutes of moderate-intensity LTPA for at least 5 days per week or spend a minimum of $600 \mathrm{METs}-\mathrm{min} /$ week, the remaining two-fifth of participants failed to engage in LTPA at the recommended level. All the participants in this study were full-time university students aged between 18-25 years old and not engaged in physically demanding labor. Hence, the low level of LTPA among the inactive group is unlikely to be due to compensatory differences in non-leisure PA [19]. Those individuals who are now inactive are at high risk to remain inactive after they leave university, and to quickly develop risk factors for non-communicable diseases.

Similar to other reports [21] [22] [23], female LTPA participation was found to be lower than their male counterparts. A hypothesis given to explain this gender difference in LTPA behavior is that boys, from their very young age, are socialized into sport roles more than girls [24] [25]. This hypothesis is very relevant in Mauritius since answers such as "parents being old-fashioned and believe that engaging in sports is not for girls" were obtained from female participants in the qualitative section of the questionnaire. Health promotion campaigns may need to particularly target our young female adults to ensure that regular LTPA participation become a norm among this important sub-group of the population.

\subsection{Motivations}

Motivations given by participants were by far mainly intrapersonal (9 out of 10). Concerns about physical health ("To avoid heart diseases", "To reduce my risk of contracting diseases ", "To Combat diabetes, high blood pressure, cholesterol", "To keep away from NCDs") were the main motivation reported by students for engaging in LTPA. Concerns about physical appearance were the second main motivation reported by participants for engaging in LTPA. Among females, the most common type of answers collected for doing LTPA was "to lose weight" and "appear slim", whereas among males, the answers were mainly of the form "to become strong and build muscles". Concerns about physical fitness, physical appearance and body image are well-known reported motivations for engaging in LTPA [19] [26]. Similar responses have been obtained from university students in Australia [27] and USA [28]. However, responses that seem to be unique to this set of university students are that some participants, especially the female participants, reported not engaging in LTPA because 
they were concerned that they might become too thin. This finding actually translates the misperception that exists among some university students that "physical activity is for fat people only'. This misperception should strongly be remedied, and the practice of LTPA to be in good health, irrespective of one's weight status must be promoted.

Fun as a motivational factor came up third in the list of factors identified by participants and was more reported by the active group than the inactive group. Various studies have shown that when LTPA is associated with fun, adherence to regular LTPA practice is increased [29] [30]. Feelings related to fun and enjoyment, have proved to be more important in maintaining regular LTPA participation than concerns about health [29]. Health promotion campaigns aimed at increasing physical activity level of young adults should therefore emphasize more on the 'fun' aspect of LTPA.

One interesting theme that came up in the analysis of motivations was the notion that the practice of LTPA had a fashionable aspect. Increasingly, the practice of LTPA is becoming a socially desirable activity. Aggressive health campaigns that are being carried out in developed countries with the support of the media showing superstars engaging in LTPA have contributed much to making LTPA 'fashionable' around the world. The present study reveals that the concept of LTPA, being regarded as a socially desirable activity, exists among university students in Mauritius.

\subsection{Constraints}

Overall, eight out of ten constraints faced by participants to engage in LTPA were of an intrapersonal nature. Lack of time came up as the most important constraint that students reported for engaging in LTPA. In many instances, the excuse of "lack of time" was co-reported with the excuse of "too many homework". Such answers actually translate a lack of time-management skills on the part of students. Young adults are not realizing that as they grow up, their responsibilities will only increase. As they enter the competitive job market, they will be asked to perform and deliver more goods at work. In addition, they will be also taking on family responsibilities. If youngsters are not able to make time for LTPA now when they are still university students, one might ask how they will make time for LTPA when they enter the professional world, have a fulltime job along with the typical family and social obligations that come along [31].

Experiencing pain during or after doing PA has been reported by participants as a constraint for engaging in LTPA. Associating pain with LTPA can ward off an individual into engaging in LTPA. Pain felt during or after an LTPA session is mainly due to inadequate warm-up before starting to exercise and due to inadequate cooling down after an exercise session. Students should be taught the correct way of exercising to limit pain and discomfort associated with LTPA to a minimum. Inclusion of a physical activity course as a degree requirement in university is one potential way of doing it. According to Pearman et al. [32], a required lifetime health and physical education course had positive effects on alumni's physical activity levels. The perception that LTPA is painful must be eliminated when individuals are still young to ensure that the present active young individuals do not associate pain with LTPA as such an association would discourage future regular practice of LTPA.

Of the three main categories (intrapersonal, interpersonal and environmental) environmental constraints were the second most reported constraint. Students' main concerns were lack of an adequate place to exercise, lack of sports equipment and safety issue. Other studies have also provided evidence highlighting the importance of physical environment on the practice of LTPA [33] [34] [35]. Providing a physical environment (in terms of facilities, accessibility and safety) that is conducive to the regular practice of LTPA has the potential to increase an entire population's LTPA participation on a relatively permanent basis. Long-term adherence to LTPA cannot be achieved by individually oriented behavior-change interventions only [35]. Changes at both the personal and environmental levels are required to achieve such a goal.

\subsection{Limitations and Strengths}

The main limitation of this research is the use of self-reported measures of LTPA. On the other hand, the use of a qualitative approach to investigate the motivations and constraints allowed us a deeper insight through a reasonable sample size used to achieve statistical significance. Proportionate stratified sampling was applied to the sample population so as to obtain representative views and opinions of all university students.

\section{Conclusion}

To date, few studies have investigated LTPA among university students in Mauritius, using an ecological perspective. Motivations and constraints faced by university students when engaging in LTPA were mainly of an intrapersonal nature. Lack of time-management skill has been identified as the main constraints in engaging in LTPA. Improvement in physical health and physical appearance were the main motivations of university students to engage in LTPA. The most interesting point in this study is the discovery of the existence of the concept that 'engaging in LTPA is fashionable' among university students. On the other hand, 'engaging in LTPA is painful' is an important misconception that was discovered from university students.

In view of the findings of the present study, it is recommended that more emphasis be laid to inculcate an LTPA culture among the students whereby daily LTPA is practiced for enjoyment. Constraints to be physically active during one's leisure time must be addressed. Health intervention campaigns to promote LTPA among university students should place particular emphasis on 
time-management skills and address the misconception that engaging in LTPA is painful. The portrayal of LTPA as a sociable and enjoyable activity that is necessary for a balanced lifestyle and that should be practiced irrespective of one's weight status should be promoted. University students need to be given incentives to develop the skills required to integrate LTPA into their daily activities, thereby reducing their future risk of chronic disease.

\section{Acknowledgment}

The authors thank Professor A. H. Subratty for constructive comments made to the manuscript.

\section{References}

[1] World Health Organization, 2007. Physical activity. Available http://www.who.int/dietphysicalactivity/publications/

[2] World Health Organization, "Global strategy on diet, physical activity and health," 2004. Available from http://www.who.int/dietphysicalactiviyt/en/

[3] M. Chan Sun, "Type 2 diabetes mellitus: A public health problem in Mauritius," London Journal of Primary Care, Feb., pp. 1-8. Available from http://www.londonjournalofprimarycare.org.uk/articles/2481 227.pdf

[4] J. E. Shaw, R.A. Sicree, P.Z. Zimmet, (2010). "Global estimates of the prevalence of diabetes for 2010 and 2030," Diabetes Res Clin Pract, vol. 87, 2010, pp. 4-14, pmid:19896746.

[5] D. J. Magliano, S. Soderberg, P. Z. Zimmet et al., (2012). "Explaining the Increase of Diabetes Prevalence and Plasma Glucose in Mauritius," Diabetes Care, vol. 35 (1), 2012, pp. 87-91.

[6] Republic of Mauritius Ministry of Health and Quality of Life, "The Trends in Diabetes and Cardiovascular Disease Risk in Mauritius," Non Communicable Diseases Survey Report, $2009 . \quad$ Available from: http://www.gov.mu/portal/goc/moh/file/ncd/ncd-2009.pdf

[7] Republic of Mauritius Ministry of Health and Quality of Life, Non Communicable Diseases Survey Report, 2004. Available http://www.gov.mu/portal/goc/moh/file/ncd/yr2004m.pdf

[8] C. J. Caspersen, M. A. Pereira and K. M. Curran, "Changes in physical activity patterns in the United States, by sex and cross-sectional age," Medicine \& Science in Sports \& Exercise, vol. 32(9), 2000, pp. 1601-9.

[9] S. R. Bray and H.A. Born, "Transition to university and vigorous physical activity: implications for health and psychological well-being," Journal of American College Health, vol.52, 2004, pp. 181-188.

[10] P. B. Sparling \& T. K. Snow, "Physical activity patterns in recent college alumni," Research Quarterly for Exercise and Sport, vol. 73, 2002, pp. 200-205.

[11] E. Leslie, P. B. Sparling and N. Owen, "University campus settings and the promotion of physical activity in young adults: lessons from research in Australia and the USA," Health Education, vol 101, 2001, pp. 116-125.

[12] P. M. Lantz, J. S. House, J. M. Lepkowski, D. R. Williams, R. P. Mero and J. Chen, "Socioeconomic factors, health behaviors, and mortality," Journal of the American Medical Association, vol. 279, 1998, pp. 1703-1708.

[13] World Health Organization, "Closing the Gap in a Generation: Health Equity Through Action on the Social Determinants of Health,". Final Report of the Commission on Social Determinants of Health, 2008.

[14] World Health Organization, "Global Physical Activity Questionnaire," 2007. [Online] Available from: http://www.who.int/chp/steps/resources/GPAQ_Analysis_G uide.pdf

[15] International Physical Activity Questionnaire. Guidelines for Data Processing and Analysis of the International Physical Activity Questionnaire. [Online] Available from: http://www.ipaq.ki.se/scoring.pdf

[16] Centers for Disease Control and Prevention, "Physical Activity for Everyone," 2007. [Online] Available from: http://www.cdc.gov/nccdphp/dnpa/physical/measuring/exam ples.htm

[17] World Health Organization, "Recommended Amount of Physical Activity," 2008. [Online] Available from: http://www.who.int/dietphysicalactivity/factsheet_recomme ndations/en/index.html

[18] D. R. Weiss, J. L O'loughlin, R. W. Platt and G. Paradis, "Five-year predictors of physical activity decline among adults in low-income communities: a prospective study," International Journal of Behavioral Nutrition and Physical Activity, vol. 4 (2), 2007.

[19] A. Haase, A. Steptoe, J. F. Sallis, J. Wardle, "Leisure-time physical activity in university students from 23 countries: associations with health beliefs, risk awareness, and national economic development," Preventive Medicine, vol. 39, 2004, pp. 182-190.

[20] Centers for Disease Control and Prevention, "Physical activity for everyone-How much exercise do you need," 2007. Available from: http://www.cdc.gov/nccdphp/dnpa/physical/everyone/recom mendations/index.htm

[21] A. A. Eyler, "Personal, social, and environmental correlates of physical activity in rural Midwestern white women," Am J Prev Med., vol. 25(3 Suppl 1), 2003, pp. 86-92.

[22] A. Schoenborn and P. Barnes, "Leisure-Time Physical Activity Among Adults: United States, 1997-98". Centers for Disease Control and Prevention, National Center for Health Statistics 2002, Advance Data No. 325.

[23] L. Jaffee, J. M. Lutter, J. Rex, C. Hawkes, P. Buccacio, "Incentives and barriers to PA for working women," Am J Health Prom., vol. 13, 1999, pp. 215-218.

[24] R. Vilhjalmsson and T. Thorlindsson, "Factors related to physical activity: a study of adolescents," Soc Sci Med., vol. 47, 1998, pp. 665-675.

[25] J. Coakley and A. White, "Making decisions: gender and sport participation among British adolescents," Sociol Sport 
J., vol 9, 1992, pp. 20-35.

[26] J. Tergerson and K. King, "Do perceived cues, benefits, and barriers to physical activity differ between male and female adolescents?," J Sch Health, vol. 72, 2002, pp. 374-380.

[27] E. Leslie, N. Owen, J. Salmon, A. Bauman, J. F. Sallis, S. K. Lo, "Insufficiently active Australian college students: Perceived personal, social, and environmental influences," Preventive Medicine, vol. 28, 1999, pp. 20-27.

[28] K. Silliman, K. Rodas-Fortier, M. Neyman, "Dietary and Exercise Habits and Perceived Barriers to Following a Healthy Lifestyle in a College Population," Californian Journal of Health Promotion, vol. 2, 2004, pp. 10-19.

[29] R. M. Ryan, C. M. Fredrick, D. Lepes, N. Rubio \& K. M. Sheldon, "Intrinsic motivation and exercise adherence," International Journal of Sport Psychology, vol. 28, 1997, pp. 335-354.

[30] R. K. Dishman, J. F. Sallis and D. R. Orenstein, "The determinants of physical activity and exercise," Public Health Rep., vol. 100, 1985, pp. 158-171.
[31] W. F. Simpson, H. N. Brehm, M. L. Rasmussen, J. Ramsay and J. C. Probst, "Health and fitness profiles of collegiate undergraduate students," Journal of exercise physiology, vol. 5(3), 2002, pp. 14-27.

[32] S. N. Pearman, R. F. Valois, R. G. Sargent, R. P. Saunders, J. W. Drane and C. A. Macera, "The impact of a required college health and physical education course on the health status of alumni," Journal of American College Health, vol. 46, 1997, pp. 77-85.

[33] N. Owen, N. Humpel, J. Salmon and P. Oja, "Environmental Influences on Physical Activity," In Health Enhancing Physical Activity Volume 6. Edited by: P. Oja, J. Borms. Berlin, Germany: International Society of Sport Science and Physical Education, 2004.

[34] J. C. Spence and R. Lee, "Toward a comprehensive model of physical activity," Psychology of Sport and Exercise. Vol. 4, 2003, pp. 7-24.

[35] C. T. Orleans, "Promoting the maintenance of health behavior change: recommendations for the next generation of research and practice," Health Psychol., vol. 19, 2000, pp. $76-83$. 